\title{
DNA methylation of the promoter region of bnip3 and bnip3/ genes induced by metabolic programming
}

\author{
Vincent Veron ${ }^{1 \dagger}$, Lucie Marandel ${ }^{1 \dagger}$, Jingwei Liu', Emilio J. Vélez², Olivier Lepais ${ }^{3}$, Stéphane Panserat ${ }^{1}$,
} Sandrine Skiba ${ }^{1}$ and Iban Seiliez ${ }^{*^{*}}$ (1)

\begin{abstract}
Background: Environmental changes of biotic or abiotic nature during critical periods of early development may exert a profound influence on physiological functions later in life. This process, named developmental programming can also be driven through parental nutrition. At molecular level, epigenetic modifications are the most likely candidate for persistent modulation of genes expression in later life.

Results: In order to investigate epigenetic modifications induced by programming in rainbow trout, we focused on bnip3 and bnip3/ paralogous genes known to be sensitive to environmental changes but also regulated by epigenetic modifications. Two specific stimuli were used: (i) early acute hypoxia applied at embryo stage and (ii) broodstock and fry methionine deficient diet, considering methionine as one of the main methyl-group donor needed for DNA methylation. We observed a programming effect of hypoxia with an increase of bnip3a and the four paralogs of bnip3/ expression level in fry. In addition, parental methionine nutrition was correlated to bnip3a and bnip3/b1 expression showing evidence for early fry programming. We highlighted that both stimuli modified DNA methylation levels at some specific loci of bnip3a and bnip3/b1.

Conclusion: Overall, these data demonstrate that methionine level and hypoxia stimulus can be of critical importance in metabolic programming. Both stimuli affected DNA methylation of specific loci, among them, an interesting CpG site have been identified, namely - 884 bp site of bnip3a, and may be positively related with mRNA levels.
\end{abstract}

Keywords: Rainbow trout, Metabolic programming, bnip3, bnip3l, Hypoxia, Methionine, DNA methylation

\section{Background}

Biotic and abiotic environmental changes encountered during critical early windows of developmental plasticity may exert a profound influence on physiological functions later in life [1]. This process named "developmental programming" has been proposed to prepare adult phenotypes to better cope with specific environment [2-4]. Over the past decades, developmental programming has been widely studied in mammals [5]. In contrast, the first studies on this topic in fish were initiated only recently and were mainly focused on nutritional and metabolic programming. In 2007, Vagner et al. showed higher and

\footnotetext{
* Correspondence: iban.seiliez@inra.fr

tVincent Veron and Lucie Marandel contributed equally to this work.

'INRA, Univ Pau \& Pays de l'Adour, E2S UPPA, UMR1419 Nutrition Metabolism and Aquaculture, Aquapôle, F-64310 Saint-Pée-sur-Nivelle, France Full list of author information is available at the end of the article
}

persistent delta 6 desaturase mRNA levels when European sea bass larvae were fed a low levels of n-3 HUFA diet [6]. In addition, an hyperglucidic diet applied at first feeding was found to lead to persistent changes in levels of transcripts related to glucose digestion and utilisation in zebrafish, gilthead seabream and rainbow trout juvenile $[2,3,7,8]$. More recently long term effects of first feeding with plant-based diet have been tested successfully in trout, salmon and seabass, confirming the concept of nutritional programming in fish [9-12].

Most of these studies applied a nutritional stimulus at first exogenous feeding. However it is known that embryogenesis also represents a sensitive window of metabolic plasticity during which a stimulus may have a more efficient long-term effect [4, 13]. For instance, an acute hypoxic stimulus applied in rainbow trout at 
embryo stage modified mRNA levels of several glucose-metabolism related genes at first feeding [14]. Moreover, after the embryonic hypoxic stimulus, the glucose metabolism in liver and muscle of rainbow trout juvenile was impacted, confirming a long term programming effect of a very early stimulus [15]. Programming can also be driven through parental nutrition. For instance, feeding rainbow trout broodstock for 6 months with a methionine deficient diet affected the expression of genes involved into methionine metabolism in fry fed for 21 days [16]. Moreover, genes involved in gluconeogenesis and autophagy were also affected by parental methionine deficiency [17]. These data confirm that developmental programming with nutritional and non-nutritional stimuli applied directly at embryo stage or through broodstock nutrition can induce long-term metabolic programming in fish.

Different biological mechanisms have been shown to be involved in developmental programming. Clonal selection of adapted cells during differential proliferation of tissue cell type could explain physiological adaptations in later life [18]. At molecular level, epigenetic modifications are the likeliest candidates to consider in the context of nutrition and more particularly when working on programming. Indeed, these mechanisms are influenced by metabolic state as well as environmental changes [19] and can be maintained at long-term during cellular divisions at least through mitosis [20], even through meiosis. In mammals, many studies have focused on mechanisms involving epigenetic regulation of genes expression and their role in nutritional or metabolic programming [21-23]. By contrast, in fish, few data are available on epigenetic mechanisms which potentially underlie programming phenotypes and are mainly limited to modifications occurring at the whole epigenome level [15, 24, 25].

In order to deeper investigate epigenetic modifications induced by environmental programming and their involvement on resulting phenotypes in teleost at target gene level, it is essential to focus on a model gene known to be sensitive to environmental changes but also regulated by epigenetic modifications in a strong and repeatable way. In the present study, we focused on bnip3 (bcl-2/E1B-19 K interacting protein 3), and bnip3like (also known as nix), two genes involved in mitochondrial mediated apoptosis and/or mitochondrial autophagy upon diverse cellular stress including hypoxia [26-28]. Changes in the expression of these two genes were previously demonstrated to be regulated by DNA methylation under hypoxic environment [29-32] but also to be associated to the activity of the one-carbon metabolism [33], the major metabolic supply route of methyl groups that are required for DNA and histone methylation.

Here, we aimed at studying epigenetic regulation of bnip3 and bnip $3 l$ genes in rainbow trout subjected to two specific stimuli known to strongly affect these genes, hypoxia and methionine deprivation, in a context of metabolic programming. First, as bnip3 and bnip3l genes can be induced by hypoxia [34-37], we studied the programming effect of an early acute hypoxic stimulus applied at embryo stage on the regulation of bnip3 and bnip3l genes at fry stage. Secondly, regarding the role of methionine as methyl donor for epigenetic modifications $[38,39]$, we investigated the programming consequences on the regulation of bnip3 and bnip3l genes on progeny of parents fed a methionine deficient diet during gametogenesis. This last step allowed investigating for the first time intergenerational programming at the epigenetic level in rainbow trout.

\section{Results}

Identification of bnip3 and bnip3/ genes in rainbow trout

Using the recent availability of the rainbow trout genome assembly [40], we identified two genes (Genoscope accession number: GSONMT00001151001 and GSONMT00 082530001) sharing a high sequence homology (E-value $>2 \mathrm{e}-09$, Sigenae tblasn http://www.sigenae.org/) with the zebrafish bnip3 available in Ensembl (ENST000 00368636.8). Similarly, we found 4 genes (Genoscope accession number: GSONMT00078967001, GSONMT0 0064944001, GSONMT00079376001 and GSONMT000 59781001) sharing a high sequence homology (E-value $>2 \mathrm{e}-16$ ) with the zebrafish bnip3la available in Ensembl (ENSDART00000035676.4).

In order to confirm the identity of the identified genes, a percentage identity matrix was established after alignment of the deduced amino acids (aa) sequences of these genes with those of BNIP3 and BNIP3L from other vertebrate species including human, mouse, chicken, lizard, coelacanth spotted gar, zebrafish, medaka and stickleback (Additional file 1: Figure S1). The identity matrix showed that the deduced aa sequences of GSONMT00001151001 and GSONMT00082530001 shared a higher percent of homology with BNIP3 (mean of $57.6 \%$ of homology) than BNIP3L (mean of $49.1 \%$ of homology). Inversely, sequences GSONMT00078967001, GSONMT00064944001, GSONMT00079376001 and GSONMT00059781001 presented a higher homology with BNIP3L (mean of $59.8 \%$ of homology) than BNIP3 (mean of $50.6 \%$ of homology) when we compared trout sequences with other studied species. Accordingly, the phylogenetic analysis performed by the Maximum Likelyhood method (Poisson model, 1000 bootstraps) showed that the two trout sequences (GSONMT00001151001 and GSONMT00082530001), sharing the highest percent of homology with BNIP3, clustered with vertebrates BNIP3, while the four last sequences (GSONMT00078967001, GSONMT0006494 4001, GSONMT00079376001 and GSONMT000597 81001) grouped together with vertebrates BNIP3L (Fig. 1). These results suggested that the two former 


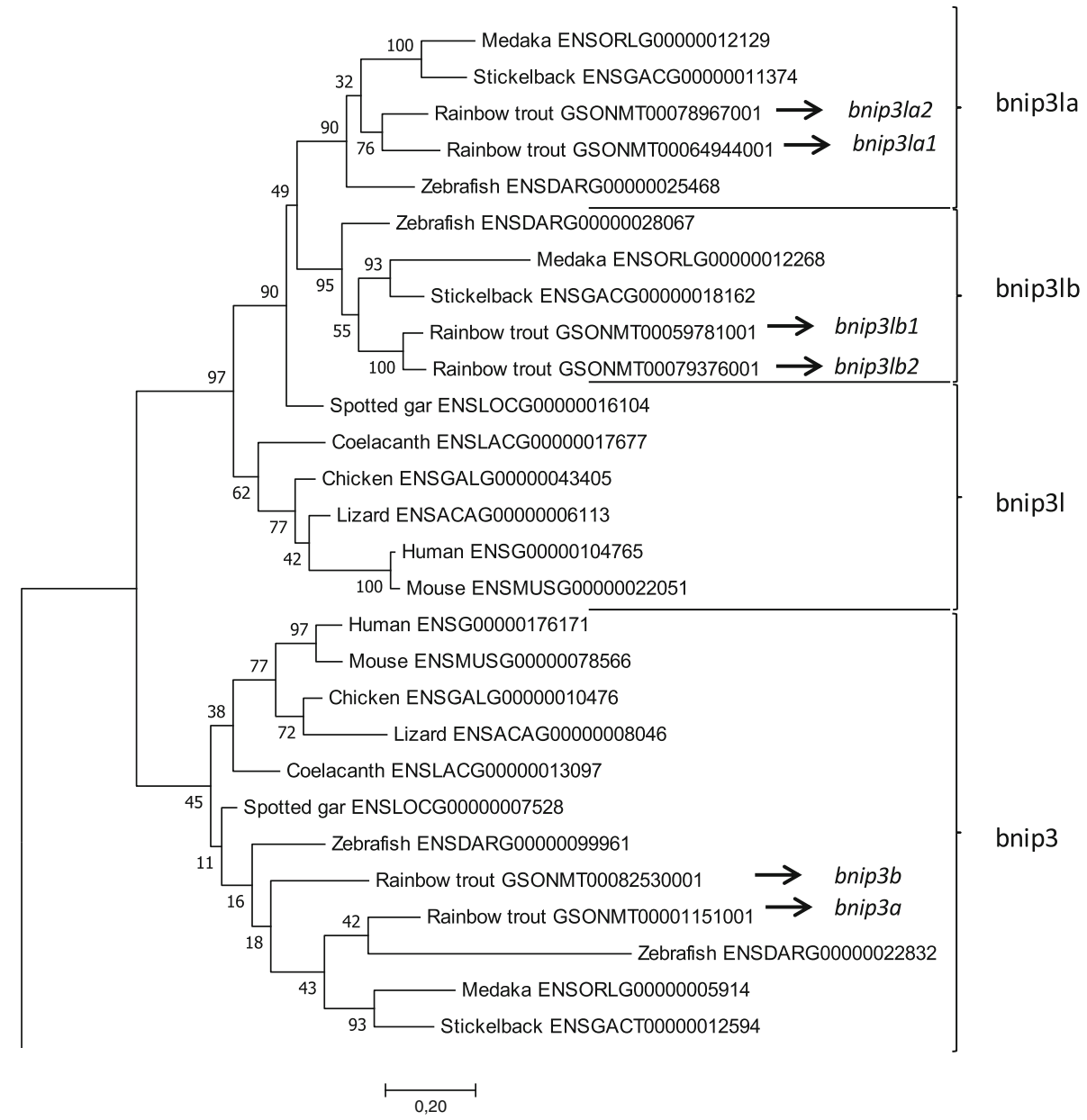

Fig. 1 Phylogenetic tree, based on full length amino acid sequences, was built using the Maximum Likelihood Method (with Poisson model) using the Molecular Evolutionary Genetics Analysis (MEGA) software version 7.0 (Tamura 2013). The reliability of the interfered trees was estimated using bootstraps with 1000 replications. Accession numbers from Ensembl or Genoscope database are in brackets. Mammalian and teleost BNIP2 protein sequences were used to root the tree

trout genes (GSONMT00001151001 and GSONMT0 0082530001) are paralogous genes and co-orthologous to vertebrates BNIP3, while the four last genes (GSONMT00078967001, GSONMT00064944001, GSON MT00079376001 and GSONMT00059781001) are co-orthologous to vertebrates BNIP3L. Moreover, this phylogenetic tree also revealed that two trout bnip3l proteins (GSONMT00064944001 and GSONMT0007896 7001) rooted with teleosts bnip3la (defining them as bnip3la1 and bnip3la2, respectively), while the two others (GSONMT00059781001 and GSONMT00079376001) were co-orthologous to bnip3lb, also identifying them as bnip3lb1 and bnip3lb2, respectively.

We then performed a syntenic analysis to clarify the evolutionary history of BNIP3 and BNIP3L in vertebrates. In all non-teleost species analysed here, bnip3 was included in the ppp2r2d-jakmip3-dpysl4-lrrc27 syntenic group highly conserved across species (Fig. 2a).
Interestingly, a syntenic conservation of this region was found in two distinct chromosomes (17 and 12) of the zebrafish genome whereas only one syntenic region containing bnip3 in medaka and stickleback was identified. Considering the newly sequenced rainbow trout genome, our syntenic analysis showed that GSONMT00001151001 (bnip3a) and GSONMT00082530001 (bnip3b) genes were localized on two distinct scaffolds (scaffold_75,456 and scaffold_95, respectively). The synteny around bnip3b locus was well conserved but the scaffold_75,456 bearing bnip3a was too short to provide relevant syntenic information. As regard bnip3l, our analysis showed a conservation of synteny in the vicinity of this locus. In all the studied vertebrates, bnip $3 l$ is included in dpysl2-ppp $2 r 2 a$ syntenic group (Fig. 2b). It should be noted that this conserved region bearing bnip3l is present in two distinct chromosomes in zebrafish, medaka and stickleback and four different scaffolds in rainbow trout. 


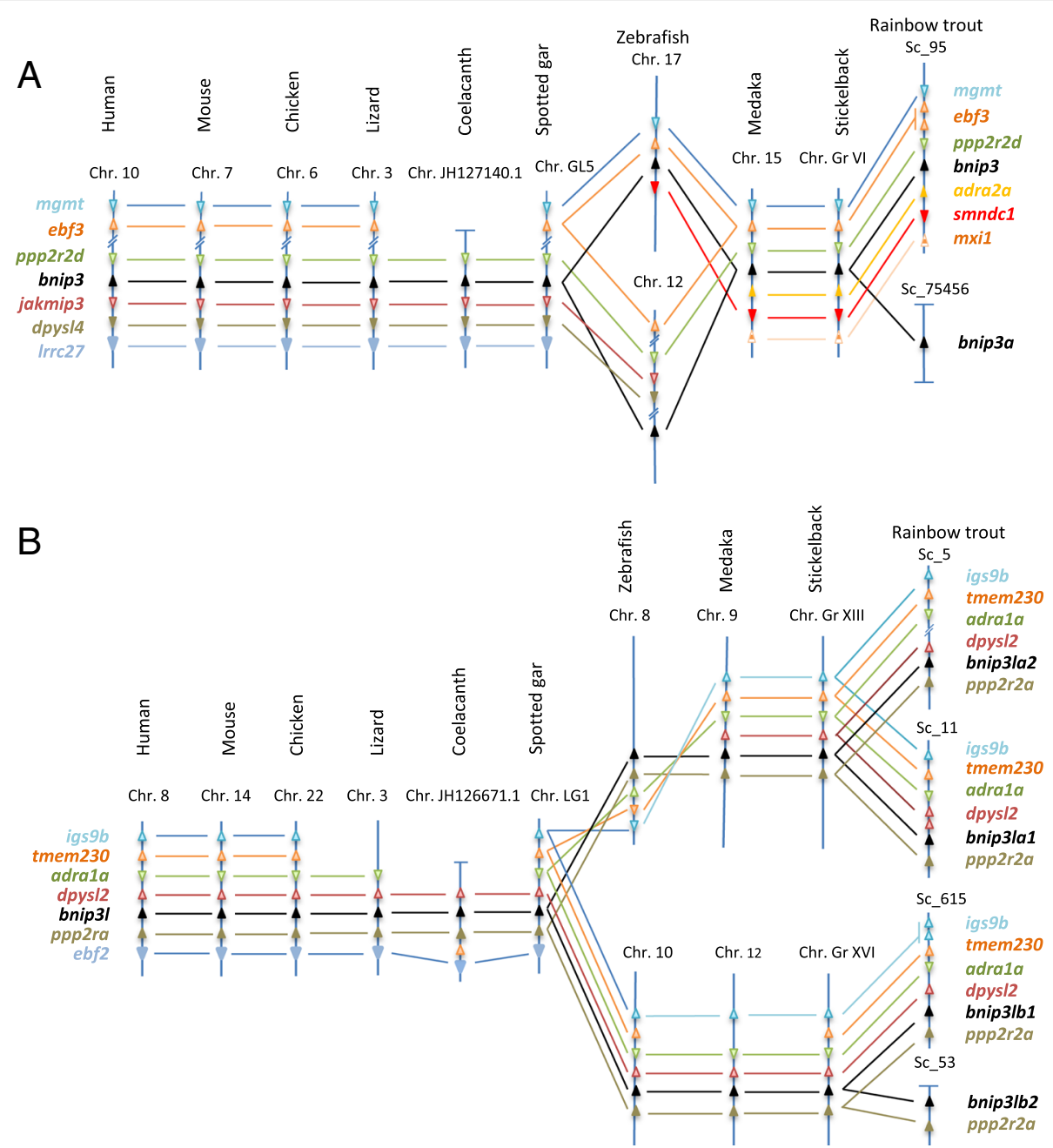

Fig. 2 Synteny around bnip3 (a) and bnip3/ (b) loci. Syntenic analyses were conducted using Genomicus software (http://wmw.genomicus.biologie.ens.fr/ genomicus-trout-01.01/

\section{bnip3 and bnip3I mRNA levels}

In mammals, hypoxia was shown to increase the expression of bnip3 and bnip3l [27, 34-36, 41, 42]. Here, we aimed to determine whether the different bnip3 and bnip3l paralogs identified in trout were affected by hypoxia as well as the possible existence of a "middle term" (until fry stage) programming effect of this stimulus on the expression of these genes. As shown in Fig. 3a, bnip3lb1 and bnip3lb2 were the only analysed genes exhibiting a significantly higher expression in embryos directly subjected to a $24 \mathrm{~h}$ hypoxic stress compared to control embryos kept at normoxic condition. However, surprisingly, at longer term $\left(502{ }^{\circ} \mathrm{D}\right.$ after hypoxia stimulus) fry from the hypoxic-embryos displayed significantly higher mRNA levels of not only bnip3lb1 and bnip3lb2 but also of bnip3a, bnip3la1 and bnip3la2 compared to the control group (Fig. 3b).

Met emerged as a key factor in modulating the cellular availability of the main biological methyl donor
S-adenosylmethionine (SAM) needed for all biological methylation reactions including DNA and histone methylation. As such, it represents a potential critical factor in nutritional programming. We therefore monitored the effect of feeding broodstock with a diet deficient in Met on the expression of identified bnip3 and bnip3l genes in offspring subjected to different dietary Met levels. We found that bnip3a and bnip3lb1 mRNA levels were induced by the Met deficiency in the diet only in offspring from Met deficient broodstock (BD-FD group significantly higher to the 3 other groups) (Fig. 4). We also found that Met deficiency applied in fry enhanced the expression of bnip3lb2 whatever the broodstock diet. All the other studied genes did not display significant changes of their expression.

Together, these results support the possibility of programming the expression of some bnip3 and bnip3l genes in rainbow trout by means of both early hypoxia stimulus and broodstock nutritional stimulus, thereby 
A
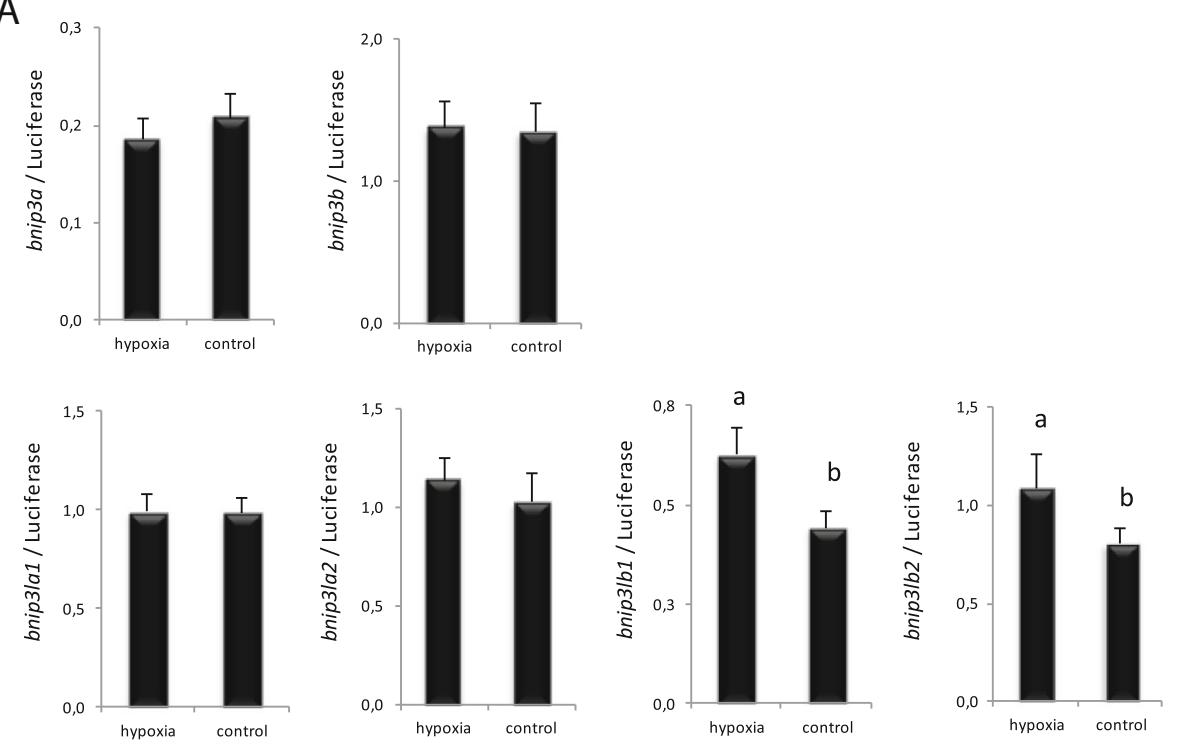

B
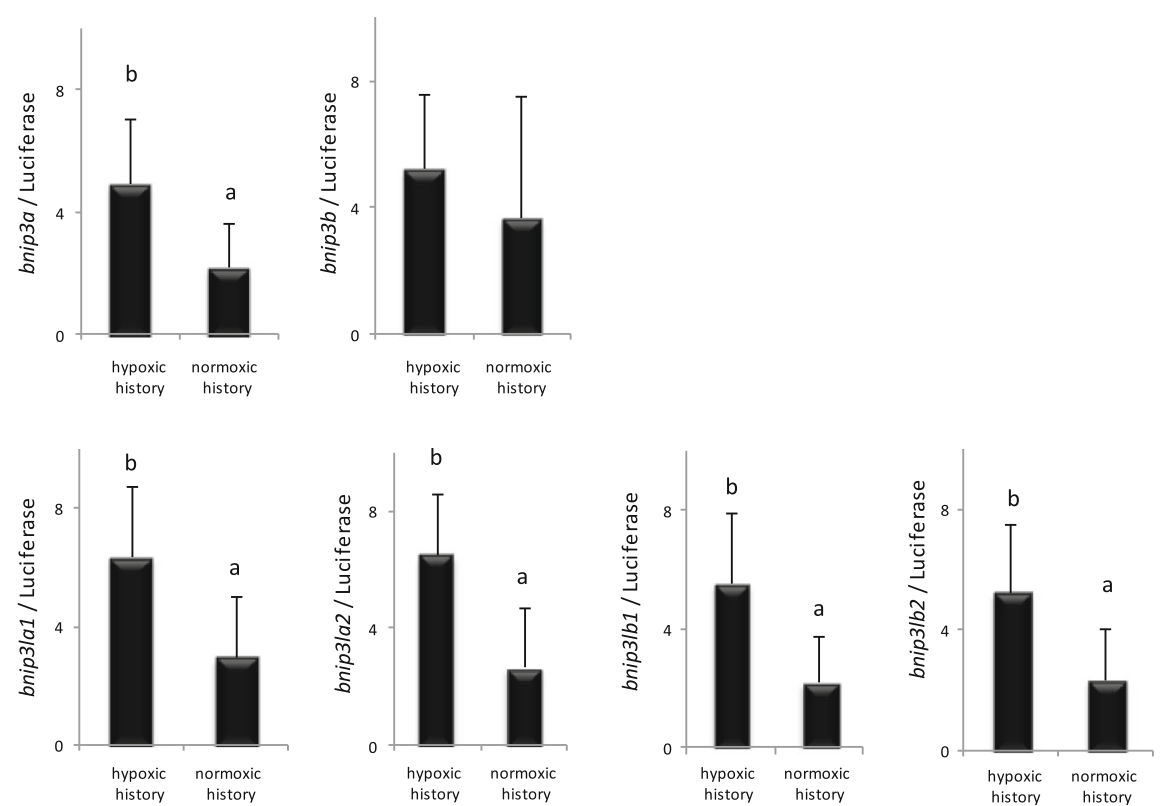

Fig. 3 Effect of hypoxic stimulus at embryo stage on mRNA levels of bnip3 and bnip3/ genes in rainbow trout embryos (a) and fry (b). Data are expressed as mean $\pm \operatorname{SE}(n=6)$. Letters indicate significant differences between conditions $(p<0.05)$

offering a good model to determine the underlying epigenetic mechanisms.

\section{bnip3 and bnip3/ promoters DNA methylation levels}

We studied the DNA methylation of bnip3 and bnip3l genes upstream region in fry of both experiments (hypoxia and Met deficiency). We focused on genes which expressions were affected by both the hypoxic stimulus and the Met deficient diet; namely bnip3a and bnip3lb1.
Using target gene Next Generation Bisulfite Sequencing, we analysed DNA methylation at specific CpG sites along the $5^{\prime}$ upstream region of these two genes.

\section{Effect of hypoxic history on DNA methylation level of bnip3a and bnip3/b1}

For both genes, we observed that the methylation level was low (from 0 to $3 \%$ ) around the ATG predicted codon and until $-600 \mathrm{bp}$ whatever the condition (data not shown). In the region upstream to $-600 \mathrm{bp}$, DNA 

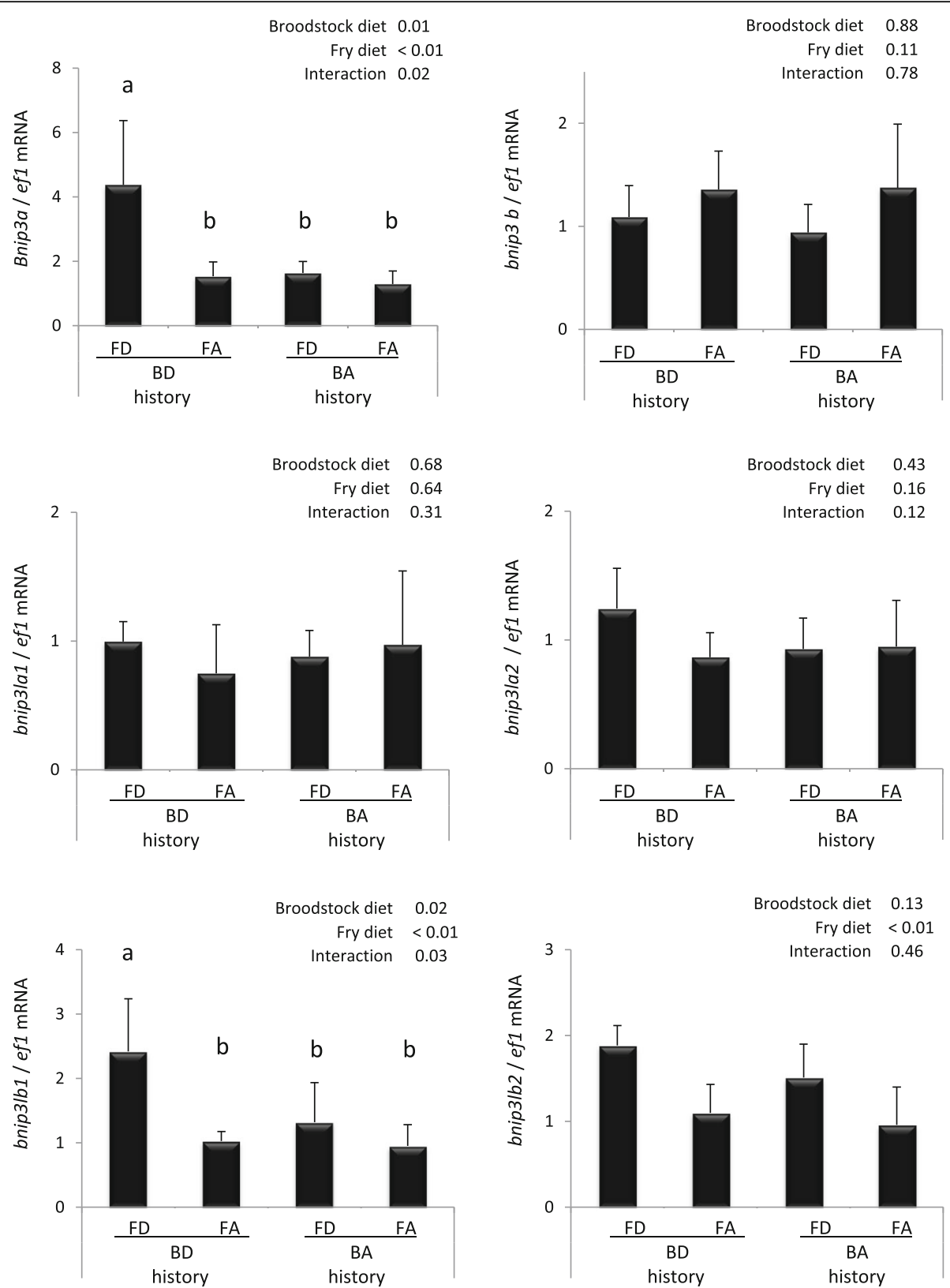

Fig. 4 Effect of a 3 weeks Met deficiency in rainbow trout fry from BD and BA broodstock groups on mRNA levels of bnip3 and bnip3l genes. BD and BA for Broodstock Deficiency and Adequate methionine diet, respectively. FD and FA for Fry Deficiency and Adequate methionine diet, respectively. Data are expressed as mean $\pm \operatorname{SE}(n=6)$. Letters indicate significant differences between conditions $(p<0.05)$

methylation levels strongly increased to reach a maximum of $70.5 \%$ and $94.5 \%$ of methylated CpG for bnip3 and bnip3l, respectively (Fig. 5a). Within this region, two CpG sites of bnip3a (at -1038 and -884 bp) and of bnip3l (at -791 and -728 bp) exhibited significantly lower methylation levels in fry with the hypoxic-history compared to their control counterparts. By contrast, the CpG sites at -848 and -653 bp of bnip $3 a$ and -818 and -814 bp of bnip3lb1 presented higher methylation rates in fry with the hypoxia history.
Effect of broodstock and/or fry fed met deficient nutrition on the level of DNA methylation of bnip3a and bnip $3 / b 1$

As for hypoxic stimulation, we observed for both genes that the DNA methylation level was very low around the ATG codon (from 0 to 2.5\%) and until - 600 bp (data not shown) whatever the condition. We also detected a strong increase of methylation levels in the regions upstream to -600 bp. As regard bnip3a, we detected two trends. The first concerns the CpG sites at -884 and $-854 \mathrm{bp}$, which showed an inhibitory effect of both the parental and fry 


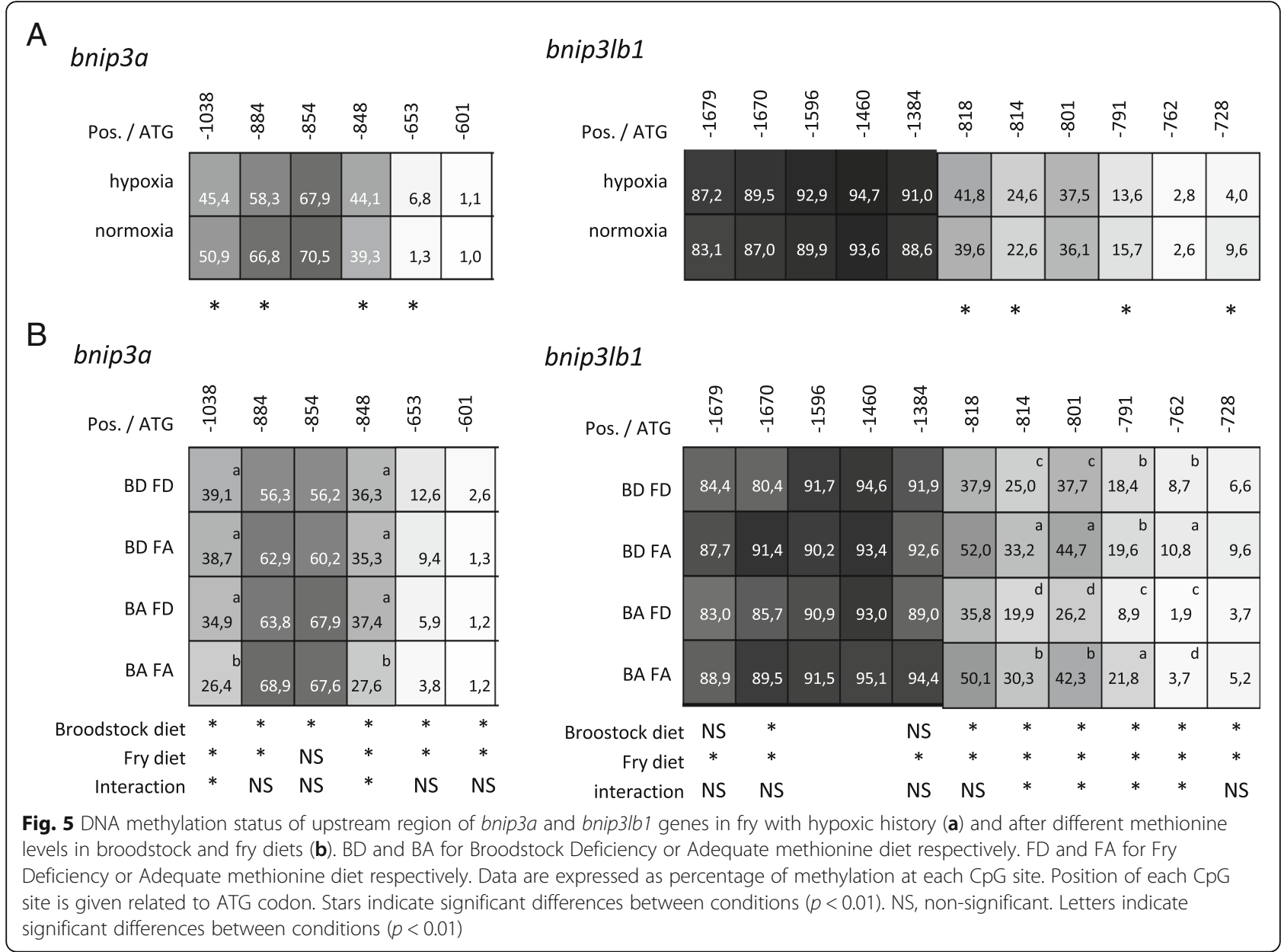

methionine deficiency on DNA methylation levels (Fig. 5b). In contrast, the CpG sites at $-1038,-848$, -653 and -601 bp showed higher DNA methylation levels upon both parental and fry methionine deficiency. As regard bnip3lb1, the CpG sites downstream of -1384 bp showed higher DNA methylation in fry from BD broodstock compared to those from BA broodstock (Fig. 5b). In contrast, the upstream CpG sites showed no effect of broodstock nutrition or even an opposite effect at $-1670 \mathrm{bp}$. In all cases (all analysed $\mathrm{CpG}$ sites), regardless of the broodstock diet, we observed a significantly lower DNA methylation levels in fry fed the methionine deficient diet.

\section{Discussion}

In this work, we aimed at studying in rainbow trout epigenetic mechanisms underlying persistent changes of bnip3 and bnip $3 l$ expression in a context of metabolic programming.

We first proceeded to the identification and characterization of the bnip3 and bnip $3 l$ genes in trout. A previous phylogenetic analysis suggested that bnip3 and bnip $3 l$ was restricted to metazoan lineage and both genes would have emerged from whole genome duplication (WGD) in the vertebrate ancestor [43]. The authors highlighted a low divergent selection pressure between both genes which was in accordance with their similar functions in apoptosis and mitophagy [26-28]. In the present study, we identified two bnip3 paralogs in rainbow trout genome assembly [40]. bnip $3 a$ and bnip3b, clustered with bnip3 teleost sequences on phylogenetic analysis. Moreover, we observed a high conserved synteny in the vicinity of bnip3 genes between the studied species. This suggests that the two rainbow trout paralogs are co-orthologous to vertebrates BNIP3 genes. It was not possible to study bnip $3 a$ synteny in rainbow trout due to a short scaffold length. However, both phylogenetic analysis and synteny suggest that the presence of two bnip3 paralogs in rainbow trout genome may be due to the recent 4th salmonid specific WGD (named Ss4R) which occurred around 80-100 million years ago $[40,44,45]$ suggesting that bnip $3 a$ and bnip $3 b$ were ohnologous genes.

We also identified four bnip3l paralogs in rainbow trout genome. Two sequences clustered with bnip3la and the remaining two with bnip3lb teleost sequences 
on the established phylogenetic tree. Furthermore, in all studied vertebrates we observed conservation of genes synteny in the vicinity of bnip3l locus. This suggests that rainbow trout bnip3l paralogs are co-orthologous to vertebrates bnip $3 l$ genes. This syntenic group is present in two distinct chromosomes in teleosts (zebrafish, medaka and stickleback) and in a unique copy in holostei (represented here by the spotted gar). Phylogenetic and syntenic data supported that the teleost-specific WGD (Ts3R) gave rise to bnip3la and bnip3lb paralogs [46-50]. Our results also showed that bnip3la1 and bnip3la2 identified in rainbow trout are co-orthologs to zebrafish, medaka and stickelback bnip3la. Similarly, bnip3lb1 and bnip3lb2 are co-orthologous with zebrafish, medaka and stickleback bnip3lb. Regarding the phylogenic and syntenic analysis, the duplication of rainbow trout bnip3la and bnip3lb genes into bnip3la1 and bnip3la2, and bnip3lb1 and bnip3lb2, respectively, arose at the Ss4R. Therefore, existence of four bnip3l paralogs in rainbow trout could be explained by two rounds of WGD, Ts3R and Ss4R. Overall, these gene duplication events of bnip $3 l$ and bnip 3 offered an interesting model to study potential divergences in both the function and the expression of the related paralogs.

Numerous studies in mammals reported that early developmental stages can be critical windows of metabolic plasticity [1]. In this regard, early life events such as nutritional or environmental changes can affect growth, health and metabolic status later in life [3, 4]. Here, we show in rainbow trout that hypoxia (applied to embryo for $24 \mathrm{~h}$ ) can induce, at least until fry stage, the expression of bnip $3 a$ and the four bnip3l paralogs. Previously, genes involved in gluconeogenesis pathway and glucose transport were reported to be affected at fry stage in same experimental conditions [15]. Therefore we confirm that hypoxia act as a developmental programming stimulus.

Our results also showed that hypoxia lead to significant changes in DNA methylation levels of upstream regions of both bnip3a and bnip3lb1. DNA methylation is often associated with gene silencing $[51,52]$. It has been observed in mammalian cancer cells, especially in hypoxic microenvironment, that BNIP3 expression is repressed by promoter aberrant hypermethylation [29, 31, 53-56]. This specific epigenetic alteration allows cancer cells to escape to BNIP3 and BNIP3L proapoptotic activity. Silencing of $B N I P 3$ expression was associated with methylation of the hypoxia-responsive element (HRE) site that in turn inhibited the binding of hypoxia-inducible factor 1 (HIF $1 \alpha)$ to the BNIP3 promoter [56]. In our study, hypoxia induced lower methylation level at CpG sites - 1038 and -884 of bnip3a and -791 and -728 of bnip3lb1. Interestingly, bnip3a displays two possible HRE at sites -1038 and 884 (data not shown), fitting consensus sequence of HRE1 and HRE2 (R-CGTC and R-CGTG, respectively), described previously $[34,57-59]$, and making possible a direct link between the hypomethylation at these specific loci and the upregulation of bnip3a expression observed in fry from the hypoxic-embryos. However, the higher methylation levels observed in neighbouring CpG sites (-848 and -653 for bnip $3 a$ and -818 and -814 for bnip3lb1) highlights the complexity of epigenetic mechanisms at play in the control of gene expression [60].

Similarly to early developmental events, parental nutrition can have an impact on growth potential, heath and metabolism of the offspring $[1,61]$. Here, we observed higher expression of both bnip $3 a$ and bnip3lb1 genes in the BD-FD group compared to other fry, supporting the existence of an early fry programming by the mean of parental nutrition. Previously, in the same experimental conditions, Seiliez et al. also reported that it was possible to drive nutritional programming in fish through parental nutrition. Met deficiency in broodstock diet affected gene expression of fatty acid, cholesterol synthesis and autophagy in fry [17]. Overall, our results confirmed that Met level can be of critical importance in metabolic programming and prompted us to investigate epigenetic mechanisms at play in the effect observed.

In mammals, early Met nutrition was shown to affect DNA methylation later on life by controlling the one-carbon metabolism [62, 63]. More recently, in zebrafish, parental deficiency of one-carbon metabolism-related metabolites was observed to affect DNA methylation levels at some specific genes loci of the offspring [64]. In the present study, we clearly demonstrated that both broodstock and early fry Met nutrition affected the methylation of several CpG sites of bnip3a and bnip3lb1 genes. However, as for hypoxia, the effect of Met deficiency (applied to both broodstock and fry) differs between the different $\mathrm{CpG}$, making difficult to depict a real picture of mechanism at play in this event. It should be noted, however, that the methylation levels at the CpG site - 884 of bnip3a (which exhibit an HRE-like sequence) may be positively related with the mRNA levels of bnip3a.

In the future, additional investigations by ChIP and promoter fusion analysis approaches should be done to better understand function of key CpG identified here. Gene regulation is complex and most of the time results from the combination of different mechanisms. For instance, histone modifications have a major impact on expression regulation by opening or condensing chromatin which enable or not transcription factor binding. Another interesting subject will be to determine whether the effects observed at fry stage persist until adult stage for both stimuli applied.

\section{Conclusion}

Collectively, we highlighted in this study modifications of DNA methylation levels of bnip3a and bnip3lb1 genes in a context of metabolic programming. An interesting 
zone has been identified, namely - 884 bp site of bnip $3 a$, which would deserve additional functional analyses in the future.

\section{Methods}

\section{Ethical issues and approval}

The INRA facilities are authorized for animal experimentation under French regulations (B 29-277-02). The experiments were carried out in accordance with the Guidelines of the National Legislation on Animal Care of the French Ministry of Research (Decree N_2001-464, May 29, 2001). The project was approved by the French National Consultative Ethics Committee (reference number 2015112018112159 and 201511201756973).

\section{In silico analysis}

The genoscope database (http://www.genoscope.cns.fr/ trout) was used to identify bnip3 and bnip3l related genes in the rainbow trout genome using BLAST analysis. Sequences are available under the accession numbers GSONMT00001151001 and GSONMT000825 30001 for bnip3 and GSONMT00064944001, GSONM T00078967001, GSONMT00059781001 and GSONMT 00079376001 for bnip3l, respectively.

Ensembl database (http://www.ensembl.org/index.html) was also used to collect amino acids deduced sequences of bnip3 and bnip3l for human, mouse, chicken, lizard, spotted gar, medaka, stickleback, zebrafish and coelacanth.

Protein alignment and the percentage Identity Matrix established with amino acids deduced sequences were performed using MUSCLE software (http://www.ebi.ac.uk/ Tools/msa/muscle/).

Phylogenetic tree, based on full length amino acid sequences, was built using the Maximum Likelihood method (with Poisson model) and confirmed by Neighbor-Joining method (data not shown) using the Molecular Evolutionary Genetics Analysis (MEGA) software version 7.0 [65]. The reliability of the interfered trees was estimated using the bootstrap method with 1000 replications. Mammalian and teleost bnip2 protein sequences were used to root the tree.

Syntenic analyses were conducted using Genomicus software (http://www.genomicus.biologie.ens.fr/genomi cus-trout-01.01/) to confirm the identity of rainbow trout genes.

\section{Experimental designs}

All fish used in this study were acquired from our INRA experimental fish farm facilities (Lées-Athas, France).

\section{Hypoxia stimulus}

The experimental design was previously described by Liu and collaborators [14] where the efficiency of the hypoxic stimulus was validated. Rainbow trout oocytes were fertilised and reared at $8{ }^{\circ} \mathrm{C}$ in 12 separate tanks in the INRA facilities (Lées-Athas, France). A $24 \mathrm{~h}$ hypoxia stimulus (2.5 mg.l ${ }^{-1}$ dissolved oxygen, $\sim 22 \%$ ) was applied in 6 tanks to embryos at 152 degree days $\left({ }^{\circ} \mathrm{D}\right)$ (Fig. 6a). The remaining 6 tanks of embryos were kept under normoxic conditions (11 mg. $\mathrm{l}^{-1}$ dissolved oxygen) as a control group. After the 24 h hypoxic stimulation, embryos were kept under normoxic conditions. After hatching, alevins were reared with natural spring water in tanks at $18{ }^{\circ} \mathrm{C}$ under natural photoperiod. At $654{ }^{\circ} \mathrm{D}$ fry fed their first meal (Additional file 2: Table S1). After $85^{\circ} \mathrm{D}$ (5 days) of feeding, fry were sampled $3 \mathrm{~h}$ after last meal by terminal anesthetization by bathing in benzocaine $(30 \mathrm{mg} / \mathrm{l}$ then a bath at $60 \mathrm{mg} / \mathrm{l})$ and were then frozen in liquid nitrogen and stored at $-80{ }^{\circ} \mathrm{C}$ until analysis. Fry which received the hypoxia at embryonic stage will be called later "fry with hypoxic-history".

\section{Methionine deficiency stimulus}

The experimental design was detailed in Fontagné-Dicharry et al. [16] and summarized in Fig. 6b. Briefly, female and male rainbow trout broodstock were reared in our experimental fish farm facilities (INRA, Lées-Athas, France), in a flow-through rearing system supplied with natural spring water $\left(8{ }^{\circ} \mathrm{C}\right)$ under natural photoperiod (April to October). Fish were randomly divided into two dietary groups (35 fish/group) that were fed for $1440{ }^{\circ} \mathrm{D}$ (6 months) before spawning one of the two plant-based diet providing two dietary methionine (Met) levels, set at 0.5 or $1 \%$ of the diet in the deficient (BD) or adequate (BA) diets, respectively (Additional file 2: Tables S2 and S3). Broodstock growth, relative fecundity, egg size and egg amino acid composition were analyzed and reported in Fontagné-Dicharry et al. [16]. Approximately 3000-5000 eggs collected for each female of each nutritional group were fertilized with a pool of sperm (collected from 5 to 8 males fed the corresponding diet). Embryos were reared at INRA experimental facilities at Lées-Athas in $8{ }^{\circ} \mathrm{C}$ stream water until the swim-up fry stage at the age of $528^{\circ} \mathrm{D}$; hatching occurred at the age of $352^{\circ} \mathrm{D}$. Following this, the swim-up fry were transferred to the experimental facilities at INRA Donzacq (France) and randomly distributed into 12 circular tanks (50 l; 400 fish/tank) supplied with natural spring water $\left(17{ }^{\circ} \mathrm{C}\right)$ under natural photoperiod. The first-feeding fry were fed during $357^{\circ} \mathrm{D}$ (3 weeks) a fry diet containing Met in adequate (FA) or deficient (FD) amounts $(n=3$ tank/diet/broodstock group) (Additional file 2: Tables S2 and S3). After 3 weeks, $n=9$ fish/tank were killed $8 \mathrm{~h}$ after the last meal by terminal anesthetization by bathing in benzocaine $(30 \mathrm{mg} / \mathrm{l}$ then a bath at $60 \mathrm{mg} / \mathrm{l})$ and were then frozen in liquid nitrogen and stored at $-80^{\circ} \mathrm{C}$ before further mRNA and DNA analyses. 
A

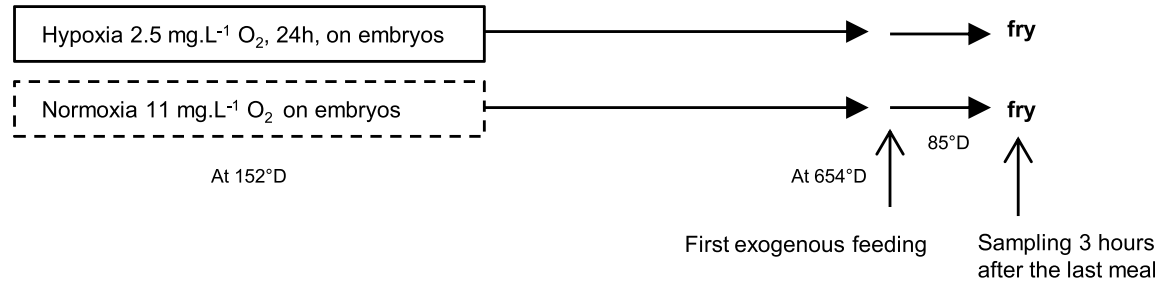

B

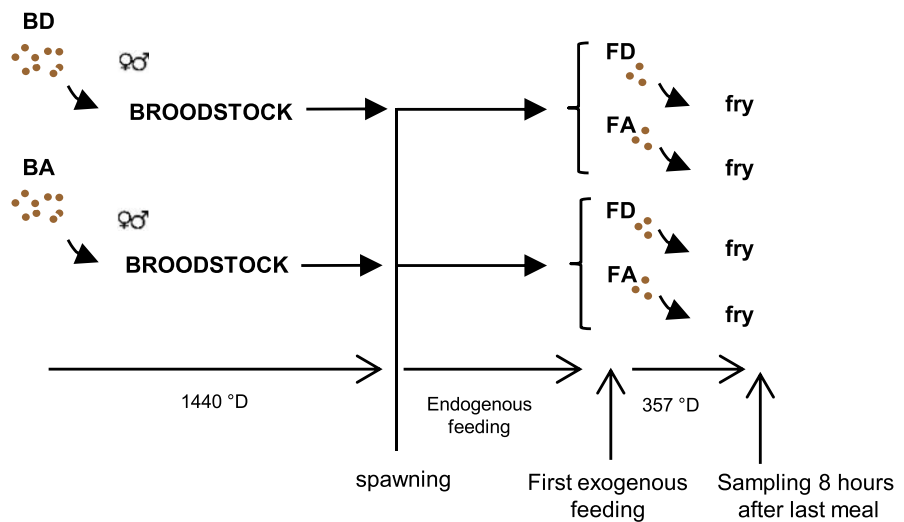

Fig. 6 Experimental design. a $24 \mathrm{~h}$ hypoxia stimulus $\left(2.5 \mathrm{mg} \cdot \mathrm{mL}^{-1} \mathrm{O}_{2}\right)$ was applied to embryos $\left(152^{\circ} \mathrm{D}\right)$. Fish were fed their first meal at $654{ }^{\circ} \mathrm{D}$. After $85^{\circ} \mathrm{D}$ of feeding, fry were sampled $3 \mathrm{~h}$ after last meal. A normoxia group was used as control. $\mathbf{b}$ Broodstock fish were fed for $1440{ }^{\circ} \mathrm{D}$ with either a methionine deficient diet (BD) or a control (Adequate, BA) diet. Males and females of each feeding group were then crossed and the obtained fry were fed with either the FD (Deficient) or the FA (Adequate) diet for $357^{\circ} \mathrm{D}$ from the first exogenous feeding

\section{RNA extraction and rtPCR}

Total RNA was extracted from the whole body of fry (six fry were extracted per condition) using the TRIzol reagent method (Invitrogen, Carlsbad, CA) with Precellys 24 (Bertin technologies, Montigny le Bretonneux, France) following Trizol manufacturer's instructions. $1 \mu \mathrm{g}$ of total RNA was reverse transcribed in duplicate with SuperScript III RNAse H Reverse Transcriptase kit (Invitrogen) and random primer (Promega) according to the manufacturer's instructions. mRNA levels were assayed using LightCycler 480 SYBR Green I Master (Roche Diagnostics, Neuilly sur Seine, France), $0.4 \mathrm{mM}$ final of each primer, $2 \mu \mathrm{l}$ of cDNA in a total volume of $6 \mu \mathrm{l}$. A LightCycler 480 II thermocycler (Roche) was used. The qPCR protocol was initiated by an initial denaturation step at $95{ }^{\circ} \mathrm{C}$ for 10 min followed by 45 cycles of a two steps amplification programme $\left(15 \mathrm{~s}\right.$ at $95{ }^{\circ} \mathrm{C}$ and $10 \mathrm{~s}$ at $\left.60{ }^{\circ} \mathrm{C}\right)$. For each sample RT and $\mathrm{qPCR}$ was run in duplicate, negative controls for RT and qPCR were included.

For hypoxia stimulus, luciferase control RNA (Promega) was used, $10 \mathrm{pg}$ per $1.9 \mathrm{mg}$ of fry added to each sample to allow data normalisation as previously described [66]. For Met deficient diet stimulus, transcripts were normalized using Elongation Factor $1 \alpha(e f 1 \alpha)$ as reference gene transcript following the Pfaffl method [67]. Primer sequences used to amplify bnip3 and bnip3l paralogs are presented in Table 1.

\section{Target gene DNA methylation study DNA extraction}

Whole body fry were digested in $5 \mathrm{ml}$ of ice cold extraction buffer (125 mM NaCl, 10 mM EDTA, 0.5\% SDS, $4 \mathrm{M}$ urea, $10 \mathrm{mM}$ tris- $\mathrm{HCl}, \mathrm{pH}=8$ ) with $80 \mu \mathrm{g} \cdot \mathrm{ml}^{-1}$ final of proteinase K (P6556, Sigma-Aldrich) overnight at $37{ }^{\circ} \mathrm{C}$ under agitation $(250 \mathrm{rpm})$. Six replicates per conditions were performed.

After overnight digestion, $5 \mathrm{ml}$ of phenol chloroform isoamyl alcohol $(25: 24: 1)$ was added to each sample. After mixing by inverting tubes, samples were centrifuged $15 \mathrm{~min}$ at $10000 \mathrm{~g}$ at room temperature. Aqueous phases were kept and $675 \mu \mathrm{l} 5 \mathrm{M} \mathrm{NaCl}$ and $5 \mathrm{ml} 100 \%$ ice-cold ethanol were added. After a 15 min centrifugation at $10000 \mathrm{~g}$ and $4{ }^{\circ} \mathrm{C}$, pellets were washed with $1 \mathrm{~mL}$ $75 \%$ ice-cold ethanol and then centrifuge again $15 \mathrm{~min}$, $10,000 \mathrm{~g}$ at $4{ }^{\circ} \mathrm{C}$. Pellets were dried and re-suspend in $\mathrm{H}_{2} \mathrm{O}$ DNase free and treated containing $2 \mu \mathrm{g}$ of RNase (R4642, Sigma) for $1 \mathrm{~h}$ at $37{ }^{\circ} \mathrm{C}$. Quality of DNA was checked on $1 \%$ agarose gel and quantification was made using Nanodrop (Thermofisher, USA). 
Table 1 Primers used for mRNA levels measurement

\begin{tabular}{llc}
\hline Gene & Primer (5' to 3') & Tm in ${ }^{\circ} \mathrm{C}$ \\
\hline bnip3a & F: CCTGTGACAGTCCTCCGAGA & 60 \\
bnip3b & R: CCACTTCACGTCTCCGTTCT & \\
& F: GAGAACAACCCACCAAAGGA & 60 \\
bnip3la1 & F: CAAACTCCACCACACCCTCT & \\
& R: CTGATCTGGACTGGGAGGTC & 60 \\
bnip3la2 & F: GGAGAGTCAGGCCCCTCAG & \\
bnip3lb1 & R: TCCTGATCTGGACTGGAAGG & \\
& R: GAACAACGGAGACGCTGGA & 61 \\
bnip3lb2 & F: GCTGTATCAGAGAACAACGGACTA & 60 \\
& R: CATGCTGAGCGTCCAGTAGA & \\
\hline
\end{tabular}

\section{Analysis of target gene methylation by targeted next-generation bisulfite sequencing}

The upstream sequence of bnip3 located on the scaffold 75,456 (GSONMT00001151001) and bnip3l located on the scaffold 615 (GSONMT00059781001) were assessed.

The sequence GSONMT00001151001 of bnip3 started 513 base pairs before the ATG codon so we sequenced the 5'UTR until - 1148 bp from ATG using the Universal GenomeWalker 2.0 (Clontech Laboratories, USA) and following manufacturer's instructions. Sanger sequencing was done by Eurofins Genomics (Paris) to identify 5'UTR region. Then, MethPrimer software (http://www.urogene .org/cgi-bin/methprimer/methprimer.cgi) [68] was used to design primers (Table 2) targeting bnip3 and bnip3l upstream regions. Each extracted DNA was bisulfite converted using EZ DNA Methylation-Gold Kit (D5005, Zymo Research, USA) following manufacturer's instructions. In order to prevent any PCR artefact, three PCR replicates were run for each bisulfite converted DNA. Advantage 2 polymerase Mix (639,206, Clontech laboratories, USA) was used for amplification. PCR conditions were $94{ }^{\circ} \mathrm{C}$ for $2 \mathrm{~min}$, and 40 cycles at $94{ }^{\circ} \mathrm{C}$ for $25 \mathrm{~s}$, melting temperature $\left(\mathrm{T}_{\mathrm{m}}\right.$ mentioned for each primers set in Table 2) for $1 \mathrm{~min}$ and $72{ }^{\circ} \mathrm{C}$ for $2 \mathrm{~min}$ followed by a final step of $7 \mathrm{~min}$ at $72{ }^{\circ} \mathrm{C}$. For each condition, all 10 amplicons (5 for each studied gene) run in triplicates were pooled. Libraries were generated using KAPA library preparation Kit (KAPA Biosystems, USA) at EpigenDx (Hopkington, USA). Sequencing was performed at EpingeDx on Ion Torrent PGM using 314 Chip kit v2. The NGS QC Toolkit v2.3.3 [69] was used to trim data removing part of the sequences with a quality score lower than 18 followed by a removal of reads smaller than 35 nucleotides using Bowtie 2 [70] using gene sequences in silico bisulfite converted as a reference. Alignment BAM files were then sorted by target and condition using BAM tools [71] split

Table 2 Primers used for target gene DNA methylation study

\begin{tabular}{|c|c|c|c|}
\hline Gene & Location from ATG & Primers ( $5^{\prime}$ to $3^{\prime}$ ) & $\mathrm{Tm}$ in ${ }^{\circ} \mathrm{C}$ \\
\hline \multirow[t]{10}{*}{ bnip3a } & \multirow[t]{2}{*}{$-1085 /-762$} & F: TGATGGAATATTTAGTITTAGTAGGATAA & \multirow[t]{2}{*}{57} \\
\hline & & R: TCCAAACCATCCAAAACTATTTAA & \\
\hline & \multirow[t]{2}{*}{$-717 /-498$} & F: TTITATGGATGGAGGAAATATTTGT & \multirow[t]{2}{*}{57} \\
\hline & & R: TAAACAACTCTCTAAACTATTAAC & \\
\hline & \multirow[t]{2}{*}{$-513 /-283$} & F: TAGAGAGTTGTITAATATAGGAAAA & \multirow[t]{2}{*}{57} \\
\hline & & R: ATCACTCACTAATATATTCATTAATC & \\
\hline & \multirow[t]{2}{*}{$-383 /-120$} & F: TTTGAATTTGTTAATAGAAATTाT & \multirow[t]{2}{*}{54} \\
\hline & & R: ATATTATTCTAATACCTCTAAATTA & \\
\hline & \multirow[t]{2}{*}{$-202 /+43$} & F: TGTITTGGTAGTTTAGTGTT & \multirow[t]{2}{*}{58} \\
\hline & & R: CCTGCAAATTTTCCT & \\
\hline \multirow[t]{10}{*}{ bnip3/b1 } & \multirow[t]{2}{*}{$-1735 /-1358$} & F: AAAGAGATAGATATTITGAGATTTGTTATA & \multirow[t]{2}{*}{57} \\
\hline & & R: TAATAAATAAATTCCACTTCACTCC & \\
\hline & \multirow[t]{2}{*}{$-1435 /-1038$} & F: TGAAGAATTGTTATGAAAGAGGTAATGT & \multirow[t]{2}{*}{57} \\
\hline & & R: TCTCCAAAACCTATATTTACCATAAAC & \\
\hline & \multirow[t]{2}{*}{$-867 /-590$} & F: GGGTATTTTAAAATTTTATTAATTTTTTATT & \multirow[t]{2}{*}{57} \\
\hline & & R: ACACTTATTTAACAATTTAACACTTATTTA & \\
\hline & \multirow[t]{2}{*}{$-594 /-222$} & F: GTGTGAGGTGAATTTAAGTTGT & \multirow[t]{2}{*}{59} \\
\hline & & R: AATAATCCAATTCTITAATAACAAAAACA & \\
\hline & \multirow[t]{2}{*}{$-252 /+26$} & F: TGTTTTGTTATTAAAGAATTGGATTATTT & \multirow[t]{2}{*}{58} \\
\hline & & R: TCAACTACAACAACAACTTCAAAC & \\
\hline
\end{tabular}


function. Sorted reads were analyzed in BiQ Analyzer HT [72] setting parameters at $100 \%$ of the read length, and bisulfite conversion efficiency $\geq 98 \%$ and lower cutoff at 20 reads per $\mathrm{CpG}$ site analyzed. The methylation level of each sampled cytosine was estimated as the number of reads reporting a $\mathrm{C}$, divided by the total number of reads reporting a $C$ or $T$. Data are expressed as percentage of methylation at each $\mathrm{CpG}$ site. Positions of $\mathrm{CpG}$ sites were determined from ATG site.

\section{Statistical analysis}

Statistical analysis of mRNA measure. For hypoxia stimulus, normality of distributions was assessed using the Shapiro-Wilk test and data were then analysed by Krustal-Wallis non-parametric test followed by Tuckey's test as post hoc analysis. For Met deficient diet stimulus, effects of broodstock diet, effects of fry diet and interaction of both factors were tested by two-way ANOVA. post hoc tests were performed using Tukey's multiple mean comparisons.

Statistical analysis of gene target methylation measure. For hypoxia stimulus, data were analyzed by a binomial generalized linear model followed by a Tukey test as a post-hoc analysis in order to test statistical significance of difference of DNA methylation observed between conditions at each CpG. For Met deficient diet stimulus, effects of broodstock diet, effects of fry diet and interaction of both factors were analysed by a binomial generalized linear model followed by Chi-square test. Tukey test as a post-hoc analysis were run to test difference between each conditions.

All statistical calculations were made using $\mathrm{R}$ software (v3.1.0)/R Commander Package [73].

\section{Additional files}

Additional file 1: Figure S1. Protein alignment and the percentage Identity Matrix established with amino acids deduced sequences were performed using MUSCLE software (http://www.ebi.ac.uk/Tools/msa/ muscle/). RT for rainbow trout. In brackets is given gene identity, 3 for BNIP3 and 3 | for BNIP3L. (PDF $167 \mathrm{~kb}$ )

Additional file 2: Table S1. Formulation and proximate composition of diet used in hypoxia stimulus [14]. Table S2. Formulation and proximate composition of diet used in methionine deficiency stimulus [16]. Table S3. Analyzed amino acid composition of the diets as $\mathrm{g} / 100 \mathrm{~g}$ dry feed used in methionine deficiency stimulus [16]. (DOCX $24 \mathrm{~kb})$

\section{Abbreviations}

BNIP3: bcl-2/E1B-19 K interacting protein3; Chip: Chromatin ImmunoPrecipitation; HUFA: Highly unsaturated fatty acids; Met: methionine

\section{Acknowledgements}

We thank the technical staff at the fish farms (F. Vallée, F. Terrier, A. Lanuque, F. Sandres, P. Maunas and N. Turonnent) for animal care and preparation of diets. We thank I. Geurden for the design of the diet formulae. Thanks to A. Surget, L. Larroquet, and K. Dias for their help with sampling and their technical assistance in the laboratory.

\section{Funding}

The part of this project concerning hypoxia has received funding from the European Union's Horizon 2020 research and innovation programme under grant agreement No. 652831 (AQUAEXCEL2020, Aquaculture infrastructures for excellence in European fish research towards 2020; "WP6 Early life history impact on later experimental fish performance").

The part of this project concerning Met deficiency diet was supported by the European Union Seventh Frame-Work programme (Project Call Identifier: FP7-KBBE-2011-5, Project number: 288925, Advanced Research Initiative for Nutrition and Aquaculture (ARRAINA). E.J.V. was supported by a predoctoral fellowship from the Ministerio de Ciencia e Innovación (MICINN), Spain. J.L. received a doctoral fellowship from the China Scholarship Council (File No. 201506330063).

\section{Availability of data and materials}

Bioinformatic data and mRNA measures generated or analysed during this study are included in this published article and its supplementary information files.

The datasets used and analysed related to targeted next-generation bisulfite sequencing during the current study are available from the corresponding author on reasonable request.

\section{Authors' contributions}

I.S, S.P and S.S designed the study. I.S and L.M managed the study. J.L and E.J.V performed the gene expression measures and statistical analysis. V.V performed methylation measures and epigenetic statistical analysis, O.L contributed to bioinformatics and statistical analysis of epigenetic data. V.V and L.M wrote the manuscript. I.S, S.P, J.L, E.J.V and S.S contributed to critically revising the manuscript. All authors have read and approved the manuscript.

\section{Ethics approval and consent to participate}

The INRA facilities are authorized for animal experimentation under French regulations (B 29-277-02). The experiments were carried out in accordance with the Guidelines of the National Legislation on Animal Care of the French Ministry of Research (Decree N_2001-464, May 29, 2001). The project was approved by the French National Consultative Ethics Committee (reference number 2015112018112159 and 201511201756973$)$.

\section{Consent for publication}

Not applicable.

\section{Competing interests}

The authors declare that they have no competing interests.

\section{Publisher's Note}

Springer Nature remains neutral with regard to jurisdictional claims in published maps and institutional affiliations.

\section{Author details}

${ }^{1}$ INRA, Univ Pau \& Pays de I'Adour, E2S UPPA, UMR1419 Nutrition Metabolism and Aquaculture, Aquapôle, F-64310 Saint-Pée-sur-Nivelle, France.

${ }^{2}$ Department of Cell Biology, Physiology and Immunology, Faculty of Biology, University of Barcelona, Barcelona, Spain. ${ }^{3}$ INRA, Univ Pau \& Pays de I'Adour, UMR Ecobiop, Aquapôle, F-64310 Saint-Pée-sur-Nivelle, France.

Received: 30 May 2018 Accepted: 31 August 2018

Published online: 17 September 2018

\section{References}

1. Lucas A. Programming by early nutrition: an experimental approach. J Nutr. 1998;128:401S-6S.

2. Geurden I, Aramendi M, Zambonino-Infante J, Panserat S. Early feeding of carnivorous rainbow trout (Oncorhynchus mykiss) with a hyperglucidic diet during a short period: effect on dietary glucose utilization in juveniles. Am J Physiol-Regul Integr Comp Physiol. 2007;292:R2275-83.

3. Geurden I, Mennigen J, Plagnes-Juan E, Veron V, Cerezo T, Mazurais D, et al. High or low dietary carbohydrate:protein ratios during first-feeding affect glucose metabolism and intestinal microbiota in juvenile rainbow trout. J Exp Biol. 2014;217:3396-406. 
4. Reynolds LP, Caton JS. Role of the pre- and post-natal environment in developmental programming of health and productivity. Mol Cell Endocrinol. 2012;354:54-9.

5. Padmanabhan V, Cardoso RC, Puttabyatappa M. Developmental programming, a pathway to disease. Endocrinology. 2016;157:1328-40.

6. Vagner M, Zambonino Infante JL, Robin JH, Person-Le Ruyet J. Is it possible to influence European sea bass (Dicentrarchus labrax) juvenile metabolism by a nutritional conditioning during larval stage? Aquaculture. 2007;267:165-74.

7. Fang L, Liang X-F, Zhou Y, Guo X-Z, He Y, Yi T-L, et al. Programming effects of high-carbohydrate feeding of larvae on adult glucose metabolism in zebrafish, Danio rerio. Br J Nutr. 2014;111:808-18.

8. Rocha F, Dias J, Geurden I, Dinis MT, Panserat S, Engrola S. Dietary glucose stimulus at larval stage modifies the carbohydrate metabolic pathway in gilthead seabream ( Sparus aurata ) juveniles: an in vivo approach using 14 C-starch. Comp Biochem Physiol A Mol Integr Physiol. 2016;201:189-99.

9. Clarkson M, Migaud H, Metochis C, Vera LM, Leeming D, Tocher DR, et al. Early nutritional intervention can improve utilisation of vegetable-based diets in diploid and triploid Atlantic salmon (Salmo salar L.). Br J Nutr. 2017;118:17-29.

10. Vera LM, Metochis C, Taylor JF, Clarkson M, Skjærven KH, Migaud H, et al. Early nutritional programming affects liver transcriptome in diploid and triploid Atlantic salmon, Salmo salar. BMC Genomics. 2017;18:886.

11. Turkmen S, Castro PL, Caballero MJ, Hernández-Cruz CM, Saleh R, Zamorano MJ, et al. Nutritional stimuli of gilthead seabream ( Sparus aurata) larvae by dietary fatty acids: effects on larval performance, gene expression and neurogenesis. Aquac Res. 2017;48:202-13.

12. Balasubramanian MN, Panserat S, Dupont-Nivet M, Quillet E, Montfort J, Le Cam A, et al. Molecular pathways associated with the nutritional programming of plant-based diet acceptance in rainbow trout following an early feeding exposure. BMC Genomics. 2016;17:449.

13. Duque-Guimarães DE, Ozanne SE. Nutritional programming of insulin resistance: causes and consequences. Trends Endocrinol Metab. 2013;24:525-35.

14. Liu J, Plagnes-Juan E, Geurden I, Panserat S, Marandel L. Exposure to an acute hypoxic stimulus during early life affects the expression of glucose metabolism-related genes at first-feeding in trout. Sci Rep. 2017;7:363.

15. Liu J, Dias K, Plagnes-Juan E, Veron V, Panserat S, Marandel L. Long-term programming effect of embryonic hypoxia exposure and high-carbohydrate diet at first feeding on glucose metabolism in juvenile rainbow trout. J Exp Biol. 2017;220:3686-94

16. Fontagné-Dicharry S, Alami-Durante H, Aragão C, Kaushik SJ, Geurden I. Parental and early-feeding effects of dietary methionine in rainbow trout (Oncorhynchus mykiss). Aquaculture. 2017;469:16-27.

17. Seiliez I, Vélez EJ, Lutfi E, Dias K, Plagnes-Juan E, Marandel L, et al. Eating for two: consequences of parental methionine nutrition on offspring metabolism in rainbow trout (Oncorhynchus mykiss). Aquaculture. 2017;471:80-91.

18. Symonds ME, Sebert SP, Hyatt MA, Budge H. Nutritional programming of the metabolic syndrome. Nat Rev Endocrinol. 2009;5:604-10.

19. Feil R, Fraga MF. Epigenetics and the environment: emerging patterns and implications. Nat Rev Genet. 2012;13:97-109.

20. Olsen AS, Sarras MP, Leontovich A, Intine RV. Heritable transmission of diabetic metabolic memory in Zebrafish correlates with DNA Hypomethylation and aberrant gene expression. Diabetes. 2012;61:485-91.

21. Burdge GC, Lillycrop KA. Nutrition, epigenetics, and developmental plasticity: implications for understanding human disease. Annu Rev Nutr. 2010;30:315-39.

22. Nijland MJ, Mitsuya K, Li C, Ford S, McDonald TJ, Nathanielsz PW, et al. Epigenetic modification of fetal baboon hepatic phosphoenolpyruvate carboxykinase following exposure to moderately reduced nutrient availability: reduced nutrient availability increases fetal baboon hepatic PEPCK. J Physiol. 2010;588:1349-59.

23. Burdge GC, Hoile SP, Uller T, Thomas NA, Gluckman PD, Hanson MA, et al. Progressive, Transgenerational changes in offspring phenotype and Epigenotype following nutritional transition. Imhof A, editor. PLoS ONE. 2011;6:e28282.

24. Marandel L, Lepais $\mathrm{O}$, Arbenoits $\mathrm{E}$, Véron V, Dias K, Zion M, et al. Remodelling of the hepatic epigenetic landscape of glucose-intolerant rainbow trout (Oncorhynchus mykiss) by nutritional status and dietary carbohydrates. Sci Rep. 2016;6:32187.

25. Panserat S, Marandel L, Geurden I, Veron V, Dias K, Plagnes-Juan E, et al. Muscle catabolic capacities and global hepatic epigenome are modified in juvenile rainbow trout fed different vitamin levels at first feeding. Aquaculture. 2017;468:515-23.
26. Zhang J, Ney PA. Mechanisms and biology of B-cell leukemia/lymphoma 2/ adenovirus E1B interacting protein 3 and nip-like protein X. Antioxid Redox Signal. 2011;14:1959-69.

27. Bellot G, Garcia-Medina R, Gounon P, Chiche J, Roux D, Pouyssegur J, et al. Hypoxia-induced autophagy is mediated through hypoxia-inducible factor induction of BNIP3 and BNIP3L via their BH3 domains. Mol Cell Biol. 2009; 29:2570-81

28. Vasagiri N, Kutala VK. Structure, function, and epigenetic regulation of BNIP3: a pathophysiological relevance. Mol Biol Rep. 2014;41:7705-14.

29. Murai M, Toyota M, Satoh A, Suzuki H, Akino K, Mita H, et al. Aberrant DNA methylation associated with silencing BNIP3 gene expression in haematopoietic tumours. Br J Cancer. 2005;92:1165-72.

30. Murai M, Toyota M, Suzuki H, Satoh A, Sasaki Y, Akino K, et al. Aberrant methylation and silencing of the BNIP3 gene in colorectal and gastric cancer. Clin Cancer Res. 2005;11:1021-7.

31. Abe T, Toyota M, Suzuki H, Murai M, Akino K, Ueno M, et al. Upregulation of BNIP3 by 5-aza-2'-deoxycytidine sensitizes pancreatic cancer cells to hypoxia-mediated cell death. J Gastroenterol. 2005;40:504-10.

32. Lazarini M, Machado-Neto JA, Duarte A d SS, Pericole FV, Vieira KP, Niemann FS, et al. BNIP3L in myelodysplastic syndromes and acute myeloid leukemia: impact on disease outcome and cellular response to decitabine. Haematologica. 2016;101:e445-8.

33. Naushad SM, Prayaga A, Digumarti RR, Gottumukkala SR, Kutala VK. BCl-2/ adenovirus E1B 19 kDa-interacting protein 3 (BNIP3) expression is epigenetically regulated by one-carbon metabolism in invasive duct cell carcinoma of breast. Mol Cell Biochem. 2012;361:189-95.

34. Bruick RK. Expression of the gene encoding the proapoptotic Nip3 protein is induced by hypoxia. Proc Natl Acad Sci U S A. 2000;97:9082-7.

35. Sowter HM, Ratcliffe PJ, Watson P, Greenberg AH, Harris AL. HIF-1dependent regulation of hypoxic induction of the cell death factors BNIP3 and NIX in human tumors. Cancer Res. 2001;61:6669-73.

36. Zhang H, Bosch-Marce M, Shimoda LA, Tan YS, Baek JH, Wesley JB, et al. Mitochondrial autophagy is an HIF-1-dependent adaptive metabolic response to hypoxia. J Biol Chem. 2008;283:10892-903.

37. Feng X, Liu X, Zhang W, Xiao W. p53 directly suppresses BNIP3 expression to protect against hypoxia-induced cell death: p53 directly suppresses BNIP3 expression. EMBO J. 2011;30:3397-415.

38. Abdul QA, Yu BP, Chung HY, Jung HA, Choi JS. Epigenetic modifications of gene expression by lifestyle and environment. Arch Pharm Res. 2017;40:1219-37.

39. Friso S, Udali S, De Santis D, Choi S-W. One-carbon metabolism and epigenetics. Mol Asp Med. 2017;54:28-36.

40. Berthelot C, Brunet F, Chalopin D, Juanchich A, Bernard M, Noël B, et al. The rainbow trout genome provides novel insights into evolution after wholegenome duplication in vertebrates. Nat Commun. 2014;5:3657.

41. Mellor HR, Harris AL. The role of the hypoxia-inducible BH3-only proteins BNIP3 and BNIP3L in cancer. Cancer Metastasis Rev. 2007;26:553-66.

42. Fei P, Wang W, Kim S, Wang S, Burns TF, Sax JK, et al. Bnip3L is induced by p53 under hypoxia, and its knockdown promotes tumor growth. Cancer Cell. 2004;6:597-609.

43. Wu X, Wu F-H, Wu Q, Zhang S, Chen S, Sima M. Phylogenetic and molecular evolutionary analysis of Mitophagy receptors under hypoxic conditions. Front Physiol. 2017:8:539.

44. Lien S, Koop BF, Sandve SR, Miller JR, Kent MP, Nome T, et al. The Atlantic salmon genome provides insights into rediploidization. Nature. 2016;533: 200-5.

45. Macqueen DJ, Johnston IA. A well-constrained estimate for the timing of the salmonid whole genome duplication reveals major decoupling from species diversification. Proc R Soc B Biol Sci. 2014;281:20132881.

46. Amores A. Zebrafish hox clusters and vertebrate genome evolution. Science. 1998;282:1711-4.

47. Christoffels A, Koh EGL, Chia J, Brenner S, Aparicio S, Venkatesh B. Fugu genome analysis provides evidence for a whole-genome duplication early during the evolution of ray-finned fishes. Mol Biol Evol. 2004;21:1146-51.

48. Jaillon O, Aury J-M, Brunet F, Petit J-L, Stange-Thomann N, Mauceli E, et al. Genome duplication in the teleost fish Tetraodon nigroviridis reveals the early vertebrate proto-karyotype. Nature. 2004;431:946-57.

49. Braasch I, Gehrke AR, Smith JJ, Kawasaki K, Manousaki T, Pasquier J, et al. The spotted gar genome illuminates vertebrate evolution and facilitates human-teleost comparisons. Nat Genet. 2016;48:427-37.

50. Taylor JS. Genome duplication, a trait shared by 22,000 species of ray-finned fish. Genome Res. 2003;13:382-90. 
51. Bird A. DNA methylation patterns and epigenetic memory. Genes Dev. 2002;16:6-21.

52. Illingworth RS, Bird AP. CPG islands - 'a rough guide. FEBS Lett. 2009;583: 1713-20.

53. An H-J, Lee H, Paik S-G. Silencing of BNIP3 results from promoter methylation by DNA methyltransferase 1 induced by the mitogen-activated protein kinase pathway. Mol Cells. 2011;31:579-83.

54. Okami J, Simeone DM, Logsdon CD. Silencing of the hypoxia-inducible cell death protein BNIP3 in pancreatic Cancer. Cancer Res. 2004;64:5338-46.

55. Bacon AL, Fox S, Turley H, Harris AL. Selective silencing of the hypoxiainducible factor 1 target gene BNIP3 by histone deacetylation and methylation in colorectal cancer. Oncogene. 2007;26:132-41.

56. Li Y, Zhang X, Yang J, Zhang Y, Zhu D, Zhang L, et al. Methylation of BNIP3 in pancreatic cancer inhibits the induction of mitochondrial-mediated tumor cell apoptosis. Oncotarget. 2017:8(38):63208-22.

57. Kothari S, Cizeau J, McMillan-Ward E, Israels SJ, Bailes M, Ens K, et al. BNIP3 plays a role in hypoxic cell death in human epithelial cells that is inhibited by growth factors EGF and IGF. Oncogene. 2003;22:4734-44.

58. Semenza GL, Jiang B-H, Leung SW, Passantino R, Concordet J-P, Maire P, et al. Hypoxia response elements in the Aldolase a, Enolase 1, and lactate dehydrogenase a gene promoters contain essential binding sites for hypoxia-inducible factor 1. J Biol Chem. 1996;271:32529-37.

59. Dengler VL, Galbraith MD, Espinosa JM. Transcriptional regulation by hypoxia inducible factors. Crit Rev Biochem Mol Biol. 2014;49:1-15.

60. Haertle L, Maierhofer A, Böck J, Lehnen H, Böttcher Y, Blüher M, et al. Hypermethylation of the non-imprinted maternal MEG3 and paternal MEST alleles is highly variable among normal individuals. Brown KW, editor. PLOS ONE. 2017;12:e0184030.

61. George LA, Zhang L, Tuersunjiang N, Ma Y, Long NM, Uthlaut AB, et al. Early maternal undernutrition programs increased feed intake, altered glucose metabolism and insulin secretion, and liver function in aged female offspring. Am J Physiol-Regul Integr Comp Physiol. 2012;302:R795-804.

62. Waterland RA, Jirtle RL. Early nutrition, epigenetic changes at transposons and imprinted genes, and enhanced susceptibility to adult chronic diseases. Nutrition. 2004;20:63-8.

63. Zeisel SH. Epigenetic mechanisms for nutrition determinants of later health outcomes. Am J Clin Nutr. 2009;89:1488S-93S

64. Skjærven KH, Jakt LM, Fernandes JMO, Dahl JA, Adam A-C, Klughammer J, et al. Parental micronutrient deficiency distorts liver DNA methylation and expression of lipid genes associated with a fatty-liver-like phenotype in offspring. Sci Rep. 2018;8:3555.

65. Tamura K, Stecher G, Peterson D, Filipski A, Kumar S. MEGA6: molecular evolutionary genetics analysis version 6.0. Mol Biol Evol. 2013;30:2725-9.

66. Marandel L, Labbé C, Bobe J, Le Bail PY. Nanog 5'-upstream sequence, DNA methylation, and expression in gametes and early embryo reveal striking differences between teleosts and mammals. Gene. 2012;492:130-7.

67. Pfaffl MW. A new mathematical model for relative quantification in real-time RT-PCR. Nucleic Acids Res. 2001;29:e45.

68. Li LC, Dahiya R. MethPrimer: designing primers for methylation PCRs. Bioinformatics. 2002;18:1427-31.

69. Patel RK, Jain M. NGS QC toolkit: a toolkit for quality control of next generation sequencing data. PLoS One. 2012;7:e30619.

70. Langmead B, Salzberg SL. Fast gapped-read alignment with bowtie 2. Nat Methods. 2012;9:357-9.

71. Barnett DW, Garrison EK, Quinlan AR, Stromberg MP, Marth GT. BamTools: a $\mathrm{C}++$ API and toolkit for analyzing and managing BAM files. Bioinformatics. 2011:27:1691-2.

72. Lutsik P, et al. BiQ analyzer HT: locus-specific analysis of DNA methylation by high-throughput bisulfite sequencing. Nucleic Acids. 2011;39:W551-6.

73. R Development Core Team. A Language and Environment for Statistical Computing [Internet]. [cited 2013 Dec 3]. Available from: http://www.r-project.org/

Ready to submit your research? Choose BMC and benefit from:

- fast, convenient online submission

- thorough peer review by experienced researchers in your field

- rapid publication on acceptance

- support for research data, including large and complex data types

- gold Open Access which fosters wider collaboration and increased citations

- maximum visibility for your research: over $100 \mathrm{M}$ website views per year

At BMC, research is always in progress.

Learn more biomedcentral.com/submissions 